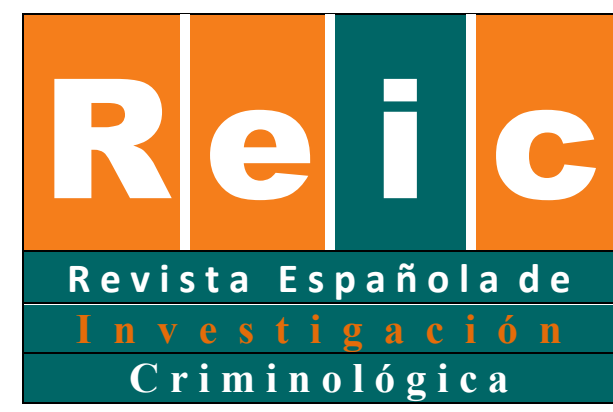

García España

\title{
Editorial
}

Elisa García España

Editora-jefe REIC

Universidad de Málaga

\section{La REIC, un camino hacia la excelencia}

Como nueva Editora-Jefe de la Revista Española de Investigación Criminológica me complace no solo presentar un nuevo número de la revista $\left(n^{0} 17\right)$, sino también dar a conocer algunos resultados alcanzados durante 2018 a las personas asociadas a la SEIC y, en general, a las que son autores, revisores y lectores de la REIC.

Aunque el nuevo equipo editorial se incorporó a mediados de 2018, la labor ha consistido prácticamente en concluir las tareas iniciadas por el equipo anterior y continuar con las pautas marcadas. Por tanto, resulta del todo necesario aprovechar estas líneas para agradecer a Santiago Redondo y a Ágata Mangot el esfuerzo realizado este tiempo atrás en la mejora de la revista, los logros alcanzados -que no son pocos-, y la ayuda que nos han prestado hasta conseguir familiarizarnos con todo el entramado de la tarea editorial.

Brevemente aportaré algunos datos que pueden darnos una idea de la actividad de la REIC durante los últimos años y especialmente durante 2018.

Revista Española de Investigación Criminológica

Editorial, Número 17 (2019)

https://doi.org/10.46381/reic.v17i0.223

www.criminologia.net

ISSN: 1696-9219 


\section{Tabla 1.}

Evolución de los manuscritos recibidos y publicado, 2016-2018

\begin{tabular}{|c|c|c|c|c|}
\hline Años & $\begin{array}{c}\text { Manuscritos } \\
\text { recibidos }\end{array}$ & Rechazos iniciales & $\begin{array}{c}\text { Rechazo tras } \\
\text { revisión }\end{array}$ & Publicados \\
\hline 2016 & 35 & 13 & 11 & 6 \\
\hline 2017 & 30 & 10 & 5 & 5 \\
\hline 2018 & 28 & 10 & 1 & 13 \\
\hline
\end{tabular}

El total de escritos recibidos no coincide con la suma de los rechazados y publicados porque algunos se publican en el año natural siguiente. Agradecemos mucho a los autores la confianza que depositan en la REIC para la publicación de sus trabajos y a los revisores por la labor desinteresada que realizan siempre y bajo la presión de los tiempos.

El reto que asume este nuevo equipo editorial se concreta en la consecución de dos objetivos clave en el camino hacia la excelencia emprendido desde la creación de la REIC:

En primer lugar, consolidar la internacionalización de la revista entre la comunidad académica de habla inglesa, impulsando la publicación de artículos en inglés. Consolidada nuestra proyección en Latinoamérica, la REIC sigue aspirando a ser un punto de encuentro de investigaciones criminológicas internacionales, así como de los grupos de investigación más punteros de nuestra disciplina. Por ello, se hace necesario seguir apostando por publicar artículos en inglés. En este sentido me complace presentar este nuevo número de la revista con 2 artículos, uno de los cuales está escrito en inglés por un autor de reconocidísimo prestigio internacional como es el profesor David Farrington. Evidentemente este hecho nos congratula ya que la contribución de tan eminente académico conseguirá una mayor difusión y proyección de nuestra revista. Estoy segura de que esta

Revista Española de Investigación Criminológica

Editorial, Número 17 (2019)

https://doi.org/10.46381/reic.v17i0.223

www.criminologia.net

ISSN: 1696-9219 
apuesta animará a otros compañeros y compañeras a publicar en inglés en la REIC para que podamos, entre todos, conseguir que esta publicación sea una referencia ineludible en el ámbito de la Criminología.

El segundo objetivo tiene relación con el primero. Seguimos apostando por la excelencia de la revista para que se sitúe y se mantenga en los listados de revistas con mayor impacto y mejores indicadores de calidad que la hagan atractiva para el envío de trabajos en inglés y castellano. En este sentido ya hay un camino recorrido de muchos años gracias a la labor llevada a cabo por los editores que me han precedido, y por la comunidad que investiga en Criminología (autores y revisores), consiguiendo que los artículos criminológicos publicados sean científicamente relevantes y con aportaciones rigurosas tanto teóricas como empíricas, ya sea con una metodología cuantitativa o cualitativa. De hecho, la REIC ya está incluida en diversos índices de calidad como Latindex, DICE, DOAJ, In-RECJ y Carhus plus. No obstante, como Editora-Jefe recojo el testigo para continuar en este camino de mejora y convergencia progresiva del proceso editorial con los patrones internacionales que inevitablemente necesitamos para incluir a la REIC en el círculo de revistas indexadas en la Journal of Citation Report.

Una de los instrumentos que van a contribuir a la consecución de este segundo objetivo es el software Open Journal Systems con el que se gestionan los envíos de los artículos y se facilita la comunicación con los autores y revisores. También la nueva interfaz de la página web de la REIC y su actualizado diseño facilitan el acceso a la información requerida. En este sentido estamos ultimando los contenidos esenciales para que esté ajustado a los estándares internacionales de excelencia. 